\title{
From Trauma to Transcendence: Clinical Perspectives on an Evolutionary Process
}

\author{
Janet Elizabeth Colli, Ph.D. \\ Seattle, WA
}

\begin{abstract}
Trauma and dissociation play a decisive role in initiating spiritual experience. This article explores transformational crises and spiritually transformative experiences (STEs) that occur within the context of trauma, physical illness, and mental disorders. Such growth or transformation may be a natural, evolutionary process, in which the defense mechanism of dissociation plays a part. Consciousness is challenged to transform when one's ego identity and defenses are threatened. Ultimately, one may arrive at a radically re-ordered conceptual framework and higher-order functioning. Acknowledgement of this evolutionary dynamic may serve as a bridge between two fields: clinical psychology, with its expertise regarding the effects of trauma, notably, dissociative states, and transpersonal psychology, with its expertise regarding transformational processes. Research from both fields is explored, as well as case examples from the author's biography, her clinical practice, and the collective. The concept of functional dissociation is introduced, and clinical considerations are addressed.
\end{abstract}

KEY WORDS: spiritually transformative experiences (STEs); transformational crisis, spiritual emergency; trauma; dissociation

"Extreme illness, car wrecks, and sexual abuse are particularly effective inducers of the mystical" (Kripal, 2001, p. 29).

"Dark places, traumas of any kind, are renowned for triggering spiritual crisis" (Lucas, 2011, p. 115).

Janet Elizabeth Colli, Ph.D., is a Licensed Mental Health Counselor in Washington state. This paper is a condensed version of her presentation at the American Center for the Integration of Spiritually Transformative Experiences (ACISTE) 3rd Annual Conference on Therapeutic Issues of Spiritually Transformative Experiences, November 6-8, 2014, Dallas, TX. Correspondence regarding this article should be sent to Dr. Colli at e-mail: becolli@mindspring.com. 
From two different approaches arise strikingly similar insight. Whether from the academic study of religion or from clinical work with spiritual emergency, a singular dynamic emerges. Trauma and dissociation play a decisive role in initiating spiritual experience. This article explores transformational crisis and spiritually transformative experiences (STEs) that occur within the context of trauma, physical illness, and mental disorders. Consciousness is challenged to transform when one's ego identity and defenses are threatened. My own autobiographical story (Colli, 2014; Siegel, 2011) will introduce this dynamic as an evolutionary process, by which I mean a development that brings about significant change and a more complex form. Ultimately, one may arrive at a radically re-ordered conceptual framework and higher-order functioning.

Trauma researcher Bessel van der Kolk has remarked that the dissociations of a culture's collective mirror the dissociations within its individual members (van der Kolk, 2011). He referred, for example, to how collective amnesia about the traumatic effects of war on individuals mirrors the traumatic dissociation of individuals who have survived war. I apply that principal to the division between clinical and transpersonal psychologies and the dissociation these fields maintain within individuals, whereby the mental disorders of clinical psychology and the near-death experiences (NDEs) and other STEs of transpersonal psychology are considered to be significantly different processes to be treated differently, both conceptually and clinically (Greyson, 2014). Considering this strategy a dissociation in need of healing, I maintain that the psycho-spiritual transformation engendered by trauma delineates the core of healing and is the meeting ground of both fields of study. I hence introduce research seminal to my own clinical work - that derives from both clinical and transpersonal psychologies - to illustrate their meeting ground. Scientific and psychological acceptance entails well-marked channels related to professional organizations such as the International Association for NearDeath Studies (IANDS) and the American Center for the Integration of Spiritually Transformative Experiences (ACISTE) for reporting such phenomena as NDEs and STEs. However, beyond the initial stages of identifying these socially "hidden events" (Westrum, 1977), the strategy of isolating these fields of psychology one from another may undercut the very process of treating and alleviating suffering. 


\section{Three Case Stories}

"The potential for a mystical experience is the natural birthright of all human beings." (Grof \& Grof, 1990, p. 22)

\section{First Case Story}

First, my own story. I was diagnosed with cancer at the age of 30. For three years after my diagnosis I focused on emotional healing and alternative medicines, avoiding allopathic or Western medical treatment. Hodgkin's lymphoma is curable, but I was medically non-compliant. My fear of it cut too close to the bones of my ego identity, which had been formed in response to multiple traumas related to Western medicine. My physician father had abused substances in an effort to self-medicate Bipolar II disorder; my mother's childhood traumas and resulting eating disorder led to my physical neglect and, ultimately, my failure to thrive. After a bout of food poisoning at approximately three years old, including traumatic hospitalization with exposure to needles, I started refusing food. I developed a non-specific eating disorder and phobias about nausea and needles that regulated my life. Radiation and chemotherapy entail nausea and needles, so in response to my cancer diagnosis, I avoided that treatment and instead embarked on a course of emotional healing and spiritual practices to initiate an STE involving spontaneous remission.

I suffered from mental illnesses whose diagnoses were unavailable at that time, namely, complex posttraumatic stress disorder (CPTSD) and developmental trauma disorder (DTD), with a resultant lack of trust in social agencies that serve a protective function (van der Kolk, 2005). Developmental trauma disorder may involve failure of different brain sectors such as the hippocampus and corpus collosum to develop fully (Felmington et al., 2009; Kitayama, Brummer, Hertz, Quinn, Kim, \& Bremner, 2007). One role of the hippocampus is to facilitate spatial memory such as navigation; my own navigation skills are extremely poorly developed. Spatial orientation of the posterior hippocampi of taxi drivers is significantly larger relative to those of control subjects (Maguire, Gadian, Johnsrude, Good, Ashburner, Frackowiak, \& Frith, 2000). However, neuroplasticity, that is, adaptive changes in neural pathways and synapses, likely facilitated a higher-order, compensatory function in my brain: I became adept at the interpretation of symbolic language, such as dreams. Anecdotal 
evidence is given below in the form of a dream interpretation that played a critical role in my healing from cancer.

Given that I suffered from traumatic stress, physical illness, as well as mental disorders, my healing highlights a dynamic. Though it did not entail an NDE that included an out-of-body experience (OBE), as with Anita Moorjani's (2014) case of untreated Hodgkin's disease, it nonetheless led to psycho-spiritual transformation.

Not until I was dying was I able to face my fears. That choice was initiated by a dream: A bulletin board next to a swimming pool announced I would be facilitating encounters between dolphins and cancer patients. Suddenly the decision to take chemotherapy and radiation was simple. The sacred archetype of water was key to the engulfment of my egoic self and the transformation of my trauma-based self-identity. Feminine fluidity: Chemotherapy began to symbolize the water element cleansing my cells. Dolphins, embodying bliss beyond ego, were the perfect agents of transformation: I saw my cancer as a call to a deeper level of love. Though I had planned to forgo allopathic medicine and heal through "natural means," my dream of dolphins ushered in a path of spiritualizing Western medicine.

Bedridden and debilitated, I took comfort in my dreams, but the dream that saved my life was far from dramatic. Its significance was subtle. I awoke refreshed and consoled by its promise, and its reassurance gave me the courage to fight. My sheer faith in that dream enabled me to make the long-dreaded decision to initiate allopathic medical treatment. Suddenly even chemotherapy and radiation were not a threat to me.

Following that dream's inspiration, I trained as a psychotherapist combining clinical psychology with a transpersonal orientation, initially working with people with disabilities related to diagnosable mental illness, notably C-PTSD due to childhood trauma, as well as physical disorders that accompanied C-PTSD, such as obesity, chronic fatigue syndrome, and fibromyalgia. Though self-selected, my clients were highly spiritualized and capable of transcendent experience often heretofore not integrated into a functional daily life.

Early recognition of the connection between trauma, altered states, and spiritual experience led me to trauma expert Judith Herman whose groundbreaking psychiatric work highlighted the role traumatic events serve as "powerful activators of the capacity for trance" (1992, p. 43). "The pathological environment of childhood abuse forces the development of extraordinary capacities, both creative and destructive [emphasis added]. It fosters the development of abnormal states of con- 
sciousness in which the ordinary relations of body and mind, reality and imagination, knowledge and memory, no longer hold" (Herman, 1992, pp. 96-97). The phenomenology of dissociation and psychosis has been differentiated from the context, content, and later recollection of STEs (Greyson, 2014). However, I note a core similarity between what Herman noted, that is, that abused children's dissociative states may alter "their sense of time, place or person" (1992, p. 102), and the standard definition of transpersonal experience as that which carries the individual beyond one's ego or self-identity, beyond culture, and sometimes beyond time and space. Herman also countenanced the capacity trauma survivors have to attain "a feeling of participation in an order of creation that transcends ordinary reality" (1992, p. 208).

Integrating trauma research and transpersonal practices, my psychotherapy practice focused on achieving functionality with dissociated states. I have come to conceptualize four stages of Psychospiritual Transformation: (1) The Shattering: Dissociation; (2) Functional Dissociation: A form of psychological absorption, facilitated with mindfulness-based consciousness practices, such as active imagination, conscious OBEs, Eye Movement Desensitization and Reprocessing (EMDR), and lucid dreaming (Esser, 2013; Miller, 2014); (3) Transcendence; and (4) Integration. It is that difference-having dissociation happen uncontrollably to oneself versus mindfully working with dissociation - that differentiates between what Herman (1992) called destructive or creative extraordinary capacities.

Other transpersonal cases included experiencers of entities other than the disembodied "divine entities" prevalent in NDEs or in most definitions of STEs. I utilized Kenneth Ring's (1992) extensive battery of self-report inventories to research the physical, personality, and value changes of my cohort, all of whom had experienced both NDEs and UFO/close encounters, and corroborated his finding of the presence of relatively high levels of childhood abuse and trauma (Colli, 2008). Experiencers were also significantly more likely than controls to attest that they were seriously ill as children. As Ring (1992) noted, a history of childhood trauma may tend to stimulate a heightened sensitivity to non-ordinary realities by virtue of a dissociative response style: a highly adaptive, psychological defense that allows one to more readily "tune into" non-ordinary realities to feel safe, regardless of what is happening to the physical body (p. 144). A correlated capacity to dissociation is psychological absorption, the ability to focus one's attention on one's inner reality to the exclusion of external events. One study of the predictors of mystical and visionary experience found 
the trait of psychological absorption to be the single most important personality variable (Nelson, 1989). Given that STErs may be more likely to attest that they were seriously ill as children, my ACISTE presentation focused on a paradigmatic case of a highly creative artist who not only experienced a transformational crisis but whose prodigious capacity for psychological absorption can be related to serious childhood illness.

\section{Second Case Story}

Singer songwriter Joni Mitchell hit her matchless stride with her cathartic album Blue, called "precise notes on a nervous breakdown, death and rebirth" (Hinton, 2000, p. 134). It was written in the language of spiritual emergency, in which one's ego defenses suffer a breakdown only to reach a re-ordering and high-order functioning (Grof \& Grof, 1990). Joni later spoke to the veils of perception being "pulled off" and the transparency of seeing. She spoke of mysticism ("I was a little 'God mad' at the time") and nervous breakdown in the same passage (Hinton, 2000, p. 98), pure visionary experience derived through psychological descent, breakdown, and dissociation. The following is material from an audiovisual documentary that I transcribed; italicized text reflects my perception of words or phrases the speaker emphasized.

And at that time in my life, [my ego defenses] just went. ... Actually it was a great spiritual opportunity but nobody around me knew it was happening.

I moved up into the Canadian backbush to a small sanctuary where I could be alone. Lived with kerosene, stayed away from electricity for about a year. I turned to nature. I was really down, and with that came a tremendous sense of knowing nothing. Western psychology might call it a nervous breakdown, but in certain cultures, they call it a shamanic conversion. So there is the possibility in that mire-of an epiphany (Lacy \& Bennett, 2003).

However, what shattered Joni Mitchell at the outset was prolonged childhood illness. "You can see in early pictures of me that I started out as an extroverted, hammy kid. But polio, scarlet fever, chicken pox bordering on smallpox, nearly dying with measles-all of that isolated me a lot" (Hinton, 2000, p. 26). Joni was nine years old when she was struck with polio and shipped by ambulance plane to Saskatoon. There, admidst terribly painful treatments, Joni longed to go home for Christmas. But the therapist dashed her hopes, saying, "You can't, 
you can't even stand up. I said, "What if I stood up and walked?" Joni fervently prayed to a small Christmas tree her mother had given her. "So I walked, I went home for Christmas. So polio, in a certain way, did me a solid-, kind of germinated an inner life, I think, also, and a sense of the mystic. Definitely, it was mystical to come back from that disease" (Lacy \& Bennett, 2003).

Ultimately, this intense act of prayer-powerfully distilled under threat of being forsaken as a "cripple"-opened Joni to an otherworldly perspective on life and unearthly powers of concentration. She spoke to her mystical connection in discussing the process of songwriting. " $A$ lot of it is being open, I think, to encounter. And in a way, in touch with the miraculous" (Lacy \& Bennett, 2003).

Songwriter Graham Nash seemed to imply that during songwriting Joni is in an altered state of consciousness:

Watching her write is a most interesting process. . . She was physically right there, but she wasn't there; she was gone. I'd say things to her, and she wasn't even listening. She was gone. And it was a great thing to see. A great thing to see someone taken away by-vision" (Lacy \& Bennett, 2003).

Joni's capacity for psychological absorption and for powerful prayer seems to be integrally linked to a capacity for dissociation. Though begun under duress of childhood illness, it likely initiated Joni into her "shamanic conversion" and the self-absorption so necessary to her artistry.

\section{Third Case Story}

"[Difficult symptoms] traditionally seen as a sign of mental illness, may actually be the organism's radical effort to free itself from the effects of various traumas, simplify its functioning, and heal itself" (Grof \& Grof, 1990, p. 24).

Defining spiritual emergency by (a) the overwhelming intensity of the process whereby it interferes with effective daily functioning, and (b) the challenge posed to one's egoic identity, I began serving individuals in the throes of spiritual emergency as well as facilitating a support group in Seattle, Washington. Individuals presented with such processes as a kundalini awakening following Panchakarma, an Ayurvedic treatment; Bipolar I, initiated by use of ketamine in a dental procedure; Bipolar II; Brief Reactive Psychosis; and PTSD in the wake of encounters with otherworldly beings. To illustrate the futility of isolating STE from mental disorders, I present the following case 
involving Reactive Attachment Disorder with diagnosed psychotic features and likely DTD. As for distinguishing STE from regressive processes, this story entails just such a regressive process, which, by virtue of its corrective nature, became spiritually transformative.

I had assisted in Clara's kundalini awakening 15 years prior. In part due to the successful negotiation of her own transformational crisis, she did not view the apparent breakdown of her 73-year-old father as a pathological regression. Withdrawing abruptly from a half-century of environmental activism and forced to rework his self-identity, John experienced insomnia for the first time in his life. As a Christmas gift, Clara had written about their times together in the wilderness. John felt deeply connected to nature wherein he had experienced unitive states of consciousness. When she read her story to the extended family, both Clara and John had intense emotional reactions. John wept openly, something unheard of. In the following months, bouts of sobbing overtook him as he expressed grief for Earth's environmental breakdown.

Following is a partial transcript (Lindstrom, 2012, p. 2) that depicts John's growing fear, anger, and confusion. John: "I'm starting to feel really afraid for when you leave...." A second later, "I'm feeling angry towards you. I've gotten dependent on you and now you're going to leave me." Then he says, "I feel this strong urge to strangle you ... and I don't know why!" Clara would remind him of his anger towards her that he'd expressed a few moments ago. "This urge is just your body feeling, and consciously recognizing this anger for the first time-it's ok! You can love me and be mad at me at the same time."

According to Clara, "His ability to identify and voice this physical urge, disturbing as it was to him, signaled the beginnings of his conscious connection to [split off, or dissociated] feelings of anger held in his body" (Lindstrom, 2012, p. 9). Clara thus helped John identify his physical urge to strangle, and as she translated from his right, emotive hemisphere to his left, verbal hemisphere, she literally acted out the role of a corpus collosum, implicated in DTD.

During the acute phase, both Clara and I were on-call during the night when John's distress was paramount. But our "container" failed to hold him, and one night we both missed his call. Given "the killing thoughts" ambushing him in the night, John insisted on being taken to the Emergency Room, afraid he was going to kill himself or somebody else. As Washington state law requires that anyone who voiced a desire to harm himself or others be under observation for 72 hours, John was admitted as a psychiatric patient. 
In hospital, John was given Ativan for sedation; the anti-psychotic, Seroquel; and Celexa, an antidepressant. Psychiatric staff frequently used the words "psychotic" and "homicidal ideations." Fortunately Clara and I saw his hospitalization as a temporary container and a chemical restraint, not as a long-lasting, healing strategy.

We formulated our own healing strategy from the emerging psychological material. John's mother had tried to adhere to the "scientifically proven" principles of child-rearing of her time: A baby shouldn't be coddled or spoiled but forced to adhere to a schedule. She'd left him to cry himself to sleep in his crib, responding only on a rigid schedule. This process was reportedly so excruciating for her that she'd sometimes force herself to leave the house rather than listen to him cry. John's response: "I learned that crying is futile! (Be stoic!)"

According to Clara, "The disrupted bonding with his mother when he was an infant helped to create a hyper-self-sufficient, skeptical, highly rational individual who has had difficulty all his life with physical touch and emotional closeness. For most of his life my father has been virtually unable to access and consciously process his own grief, fear, and other "negative" emotions. He has not been able to ask for help. Or express anger towards those he loves" (Lindstrom, 2012, p. 30).

The neuroscience of developmental psychology confirms long-term relational deficits due to a consistent lack of attunement in infancy (Wilkinson, 2010). What is striking is that this distressing image of being left alone in a crib consistently emerged for John, as did spontaneous corrective experiences. Overwhelmed with sadness and anger towards his mother, unable to sleep, and desperate for relief from anxiety, John curled up in the bathtub with warm water running over him:

EXTREMELY SOOTHING. I imagined the water from ALL TIME cascading over me and carrying me along in the cosmos.... The patter of drops was like a touching caress from Mother Earth . . . lying there in the tub ... it's sorta like I was going back to being a baby. Starting from scratch. (Lindstrom, 2012, p. 34)

During a family therapy session after his release from hospital, John responded to the internal and external pressure he was feeling, as his family challenged him to "face this scary stuff." After a long silence, he put his head in his hands, leaned forward, and made a low moaning sound. Recognizing that he was entering a deep altered state, I readied the room for breathwork to facilitate it. As it happened, John's process unfolded quite naturally as, without urging, he began 
taking "deep, rackety breaths as he rocked back and forth . ..., and he let go with a long, heart-shattering wail: 'Mommmm. . . ! Where WERE youuuu. . . . ?' and burst into sobs" (Lindstrom, 2012, p. 37).

Clara eloquently wrote:

Never in my life have I witnessed anything so profound. I was completely stunned. I had the acute sense that I was watching an ecological process, a force of nature in motion, like waves crashing or leaves unfurling. It was the most arresting, guileless, palpably moving display I have ever seen. This was clearly not coming from mind, or a rational place, but rather from a much deeper level. A well of soul. (Lindstrom, 2012, p. 37)

After that cathartic session, which included breathwork and evocative music, John wrote,

I could feel as if I was 2 years old and re-living that time of my life. It did not feel like regression, however. It felt like re-contacting, reconnecting ... I felt that my mother was very sad and crying about what happened when I was an infant. She was saying, "I'm sorry" over and over. Intellectually I know that she had been very averse to the child rearing practices promoted in the 1930's. Now, I felt her remorse in a very emotional, direct way. (Lindstrom, 2012, p. 38)

A further session of Holotropic Breathwork helped to familiarize John with deep emotion and to process the grief within his body. His crisis rapidly subsided, leaving John with a more empathetic perspective, both for himself as well as others, and a larger range of emotional expression. John had formerly attained a spiritual connection with nature. His unique STE transpired through the vehicle of his own physical and emotional bodies, and his deep connection to nature (externally) became more fully integrated with nature (internally). I am reminded of the Gnostic Gospel according to Thomas: "When you make the two one, and when you make the inner as the outer and the outer as the inner and the above as the below ... then shall you enter [the Kingdom]" (Thomas, 1959 trans.).

Three clinical considerations are apparent from Clara and John's story: (a) the importance of a healing perspective, as Clara exemplifies in the following. "What appeared, on the surface, to be the pathological process of an individual man was actually part of the larger story of our species waking up" (Lindstrom, 2012); (b) the potentially triggering impact that the close physical proximity of someone who has already undergone a transformational crisis may have upon a vulnerable individual; and (c) the need for a safe, supportive container, preferentially residential. 
With the above case stories I have attempted to illustrate the role that trauma and dissociation can play in laying the foundation for later spiritually transformative experience. Beyond the scope of this paper, recent clinical work speaks to the transformation within psychology and psychiatry that is sparked when the evolutionary dynamic of transformational crisis - through trauma and dissociation-is supported (Blackwell, 2011; Colli, 2014; Lucas, 2011; Romme, 2012; Williams, 2012).

\section{References}

Blackwell, S. (2011). Am I bipolar or waking up? Amazon.com: CreateSpace Independent Publishing Platform.

Colli, J. (2014). The dark face of heaven: True stories of transcendence through trauma. Amazon.com: CreateSpace Independent Publishing Platform.

Colli, J. (2008). Angels and aliens: Encounters with both near-death \& UFOs. In F. Fernandes, R. Fernandes, \& R. Berenguel (Eds.), Fatima revisited: The apparition phenomenon in Ufology, psychology, and science (pp. 172-185). San Antonio, TX: Anomalist Books.

Esser, T. (2013). Lucid dreaming, kundalini, the divine, and nonduality: A transpersonal narrative study. Unpublished Doctoral Dissertation, California Institute of Integral Studies.

Felmingham, K., Wiliams, L. M., Whitford, T. J., Falconer, E., Kemp, A. H., Peduto, A., et al. (2009). Duration of posttraumatic stress disorder predicts hippocampal grey matter loss. Neuroreport, 20(16), 1402-1406.

Greyson, B. (2014). Differentiating spiritual and psychotic experiences: Sometimes a cigar is just a cigar. Journal of Near-Death Studies, 32(3), 123-136.

Grof, C., \& Grof, S. (1990). The stormy search for the self. New York, NY: G. P. Putnam's Sons.

Herman, J. (1992). Trauma and recovery. New York, NY: Basic Books.

Kitayama N., Brummer, M., Hertz, L., Quinn, S., Kim, Y., \& Bremner, J. D. (2007). Morphologic alterations in the corpus callosum in abuse-related posttraumatic stress disorder. Journal of Nervous Mental Disorders, 195(12), 1027-1029.

Kripal, J. (2001). Roads of excess \& palaces of wisdom: Eroticism \& reflexivity in the study of mysticism. Chicago, IL: University of Chicago Press.

Hinton, B. (2000). Both sides now: The biography. London, England, UK: Sanctuary.

Lacy, S., \& Bennett, S. (Producers). (2003). American masters: Joni Mitchell: Woman of heart and mind. New York, NY: Eagle Rock Entertainment and Thirteen/WNET.

Lindstrom, C. (2012). Better living through chemistry? Not necessarily. An exploration of mental health and who defines it. Unpublished manuscript.

Lucas, C. G. (2011). In case of spiritual emergency: Moving successfully through your awakening. Findhorn, Scotland, UK: Findhorn Press.

Maguire, E. A., Gadian, D. G., Johnsrude, I. S., Good, C. D., Ashburner, J., Frackowiak, R. S., \& Frith, C. D. (2000). Navigation-related structural change in the 
hippocampi of taxi drivers. Proceedings of the National Academy of Sciences, 97(8), 4398-4403. doi: 10.1073/pnas.070039597.

Miller, M. (2014). Healing complex trauma through eye movement desensitization and reprocessing and transpersonal psychotherapy: Psychotherapists' heuristic exploration of integration compatibility and transformative value. Unpublished Doctoral Dissertation, Institute of Transpersonal Psychology, Palo Alto, CA.

Moorjani, A. (2014). Dying to be me: My journey from cancer, to near death, to true healing. Carlsbad, CA: Hay House.

Nelson, P. L. (1989). Personality factors in the frequency of reported spontaneious preternatural experiences. Journal of Transpersonal Psychology, 21, 193-209.

Ring, K. (1992). The omega project: Near-death experiences, UFO encounters, and mind at large. New York, NY: William Morrow.

Romme, M., \& Escher, S. (2012). Psychosis as a personal crisis. New York, NY: Routledge.

Siegel, B. S. (2011). A book of miracles: Inspiring true stories of healing, gratitude, and love. Novato, CA: New World Library.

Thomas. (1959). The gospel according to Thomas: The gnostic sayings of Jesus (A. Guillaumont, H. C. Puech, G. Quispel, W. Till, and Yassah 'Abd al Masih, Trans.). San Francisco, CA: Harper \& Row.

van der Kolk, B. (2005). Developmental trauma disorder: Toward a rational diagnosis for children with complex trauma histories. Psychiatric Annals, 35(5), 401-408.

van der Kolk, B. (2011). 22nd Annual Trauma Conference: Psychological trauma: Neuroscience, attachment \& interventions (DVD). Eau Claire, WI: Premier Education Solutions.

Westrum, R. (1977). Social intelligence about anomalies: The case of UFOs. Social Studies of Science, 7, 271-302.

Wilkinson, M. (2010). Changing minds in therapy: Emotion, attachment, trauma \& neurobiology. New York, NY: W. W. Norton.

Williams, P. (2012). Rethinking madness: Towards a paradigm shift in our understanding and treatment of psychosis. San Rafael, CA: Sky's Edge. 